\title{
Tujuan dan pengenalan Sistem Operasi
}

\author{
MOH TEGAR TRI PRAKOSA \\ 195120050 \\ Fakultas Komputer \\ Moh.student@umitra.ac.id
}

\section{PENGENALAN SISTEM OPERASI}

Sistem operasi merupakan sebuah penghubung antara pengguna dari komputer dengan perangkat keras komputer. Sebelum ada sistem operasi, orang hanya mengunakan komputer dengan menggunakan sinyal analog dan sinyal digital.

Seiring dengan berkembangnya pengetahuan dan teknologi, pada saat ini terdapat berbagai sistem operasi dengan keunggulan masing-masing. Untuk lebih memahami sistem operasi maka sebaiknya perlu diketahui terlebih dahulu beberapa konsep dasar mengenai sistem operasi itu sendiri.

\section{Definisi Sistem Operasi}

Sistem komputer pada dasarnya terdiri dari empat komponen utama, yaitu perangkat keras, program aplikasi, system operasi, dan para pengguna. Sistem operasi berfungsi untuk mengatur dan mengawasi penggunaan perangkat keras oleh berbagai program aplikasi serta para pengguna. menjalankan program secara benar. Untuk 
menghindari konflik yang terjadi pada saat pengguna menggunakan sumber daya yang sama, sistem operasi mengatur pengguna mana yang dapat mengakses suatu sumber daya.

Sistem operasi juga sering disebut resource allocator. Satu lagi fungsi penting sistem operasi adalah sebagai program pengendali yang bertujuan untuk menghindari kekeliruan (error) dari penggunaan komputer yang tidak perlu.

- Tujuan Mempelajari Sistem Operasi

Mempelajari Sistem Operasi bertujuan agar nantinya mengenal dan mampu merancang sendiri serta dapat memodifikasi sistem operasi yang telah ada sesuai dengan kebutuhan kita. Juga agar bisa memilih alternatif sistem operasi, memaksimalkan penggunaan sistem operasi, sehingga konsep dan teknik sistem operasi dapat diterapkan pada aplikasi-aplikasi lain.

\section{Sasaran Sistem Operasi}

Sistem operasi mempunyai tiga sasaran utama yaitu:

1. Kenyamanan, yaitu membuat penggunaan komputer menjadi lebih nyaman.

2. Efisien, yaitu agar penggunaan sumber daya dalam sistem komputer dapat digunakan secara efisien.

3. Mampu berevolusi, yaitu dalam membangun sistem operasi dimungkinkan untuk lebih mudah dalam pengembangan, pengujian, serta penggunaan sistem-sistem yang baru. 


\section{Sejarah Sistem Operasi}

Menurut Tanenbaum, sistem operasi mengalami perkembangan yang sangat pesat, yang dapat dibagi ke dalam empat generasi:

\section{Generasi Pertama (1945-1955)}

Generasi pertama merupakan awal perkembangan sistem komputasi elektronik sebagai pengganti sistem komputasi mekanik, hal itu disebabkan kecepatan manusia untuk menghitung terbatas dan manusia sangat mudah untuk membuat kecerobohan, kekeliruan bahkan kesalahan.

Pada generasi ini belum ada sistem operasi, maka sistem komputer diberi instruksi yang harus dikerjakan secara langsung.

II. Generasi Kedua (1955-1965)

Generasi kedua memperkenalkan Batch Processing System, yaitu Job yang dikerjakan dalam satu rangkaian, lalu dieksekusi secara berurutan. Pada generasi ini sistem komputer belum dilengkapi sistem operasi, tetapi beberapa fungsi sistem operasi telah ada, contohnya fungsi sistem operasi ialah FMS dan IBSYS.

\section{Generasi Ketiga (1965-1980)}

Pada generasi ini perkembangan sistem operasi dikembangkan untuk melayani banyak pemakai sekaligus, di mana para pemakai interaktif berkomunikasi lewat terminal secara online ke komputer, maka sistem operasi menjadi multi-user (digunakan banyak 
pengguna sekaligus) dan multi-programming (melayani banyak program sekaligus).

\section{Generasi Keempat (Pasca 1980an)}

Di generasi keempat, sistem operasi sudah dipergunakan untuk jaringan komputer dimana pemakai menyadari keberadaan komputer-komputer yang saling terhubung satu sama lainnya.

\section{Layanan Sistem Operasi}

Sebuah sistem operasi yang baik menurut Tanenbaum, harus memiliki layanan sebagai seperti:

1. Pembuatan program yaitu sistem operasi menyediakan fasilitas dan layanan untuk membantu para pemrogram untuk menulis program.

2. Eksekusi Program yang berarti Instruksiinstruksi dan data-data harus dimuat ke memori utama, perangkat-parangkat masukan/keluaran dan berkas harus diinisialisasi, serta sumberdaya yang ada harus disiapkan, semua itu harus ditangani oleh sistem operasi

3. Pengaksesan I/O Device, artinya Sistem Operasi harus mengambil alih sejumlah instruksi yang rumit dan sinyal kendali agar pemrogram dapat berfikir sederhana dan perangkat pun dapat beroperasi. 
Pada masa ini para pengguna juga telah dinyamankan dengan Graphical User Interface(GUI) yaitu antar-muka komputer yang berbasis grafis yang sangat nyaman, juga dimulai era komputasi tersebar dimana komputasi-komputasi tidak lagi berpusat di satu titik tetapi dipecah dibanyak komputer sehingga tercapai kinerja yang lebih baik.

\section{E. Layanan Sistem Operasi}

Sebuah sistem operasi yang baik menurut Tanenbaum, harus memiliki layanan sebagai seperti:

1. Pembuatan program yaitu sistem operasi menyediakan fasilitas dan layanan untuk membantu para pemrogram untuk menulis program.

2. Eksekusi Program yang berarti Instruksi-instruksi dan data-data harus dimuat ke memori utama, perangkat-parangkat masukan/keluaran dan berkas harus diinisialisasi, serta sumber-daya yang ada harus disiapkan, semua itu harus ditangani oleh sistem operasi

3. Pengaksesan I/O Device, artinya Sistem Operasi harus mengambil alih sejumlah instruksi yang rumit dan sinyal kendali agar pemrogram dapat berfikir sederhana dan perangkat pun dapat beroperasi.

4. Pengaksesan terkendali terhadap berkas, yang artinya disediakannya mekanisme proteksi terhadap berkas untuk mengendalikan pengaksesan terhadap berkas.

5. Pengaksesan sistem, artinya pada pengaksesan digunakan bersama (shared system).

6. Fungsi pengaksesan, yaitu menyediakan proteksi terhadap sejumlah sumber-daya dan data dari pemakai serta menyelesaikan konflik-konflik dalam perebutan sumber-daya.

7. Deteksi dan pemberian tanggapan pada kesalahan, yaitu jika muncul permasalahan muncul pada sistem komputer maka sistem operasi harus memberikan tanggapan yang menjelaskan kesalahan 
yang terjadi serta dampaknya terhadap aplikasi yang sedang berjalan.

8. Akunting, yang artinya sistem operasi harus bisa mengumpulkan data statistik penggunaan beragam sumber-daya dan memonitor parameter kinerjanya.

\section{F. STRUKTUR KOMPUTER}

Struktur komputer didefinisikan sebagai cara-cara dari setiap komponen yang saling terkait. Struktur sebuah komputer secara sederhana, dapat digambarkan dalam diagram blok pada gambar dibawah.

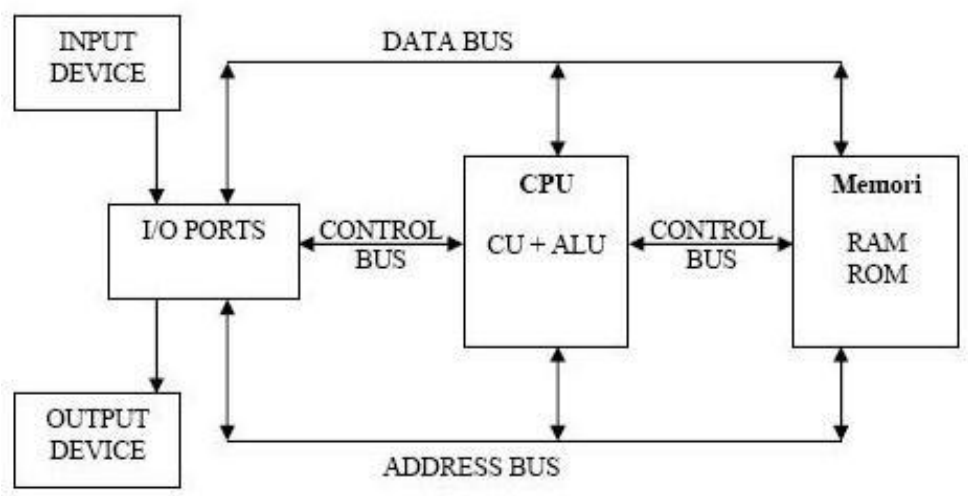




\section{A. ID SECURITY}

QWTD44112377-ASP-524414475

\section{B. REFERENCE}

[1] O. M. Febriani and A. S. Putra, "Sistem Informasi Monitoring Inventori Barang Pada Balai Riset Standardisasi Industri Bandar Lampung," J. Inform., vol. 13, no. 1, pp. 90-98, 2014.

[2] A. S. Putra, "Paperplain: Execution Fundamental Create Application With Borland Delphi 7.0 University Of Mitra Indonesia," 2018.

[3] A. S. Putra, "2018 Artikel Struktur Data, Audit Dan Jaringan Komputer," 2018.

[4] A. S. Putra, "ALIAS MANAGER USED IN DATABASE DESKTOP STUDI CASE DB DEMOS."

[5] A. S. Putra, "COMPREHENSIVE SET OF PROFESSIONAL FOR DISTRIBUTE COMPUTING."

[6] A. S. Putra, "DATA ORIENTED RECOGNITION IN BORLAND DELPHI 7.0."

[7] A. S. Putra, "EMBARCADERO DELPHI XE 2 IN GPU-POWERED FIREMONKEY APPLICATION."

[8] A. S. Putra, "HAK ATAS KEKAYAAN INTELEKTUAL DALAM DUNIA TEKNOLOGY BERBASIS REVOLUSI INDUSTRI 4.0."

[9] A. S. Putra, "IMPLEMENTASI PERATURAN PERUNDANGAN UU. NO 31 TAHUN 2000 TENTANG DESAIN INDUSTRI BERBASIS INFORMATION TECHNOLOGY."

[10] A. S. Putra, "IMPLEMENTATION OF PARADOX DBASE."

[11] A. S. Putra, "IMPLEMENTATION OF TRADE SECRET CASE STUDY SAMSUNG MOBILE PHONE."

[12] A. S. Putra, "IMPLEMENTATION PATENT FOR APPLICATION WEB BASED CASE STUDI WWW. PUBLIKLAMPUNG. COM." 
[13] A. S. Putra, "IMPLEMENTATION SYSTEM FIRST TO INVENT IN DIGITALLY INDUSTRY."

[14] A. S. Putra, "MANUAL REPORT \& INTEGRATED DEVELOPMENT ENVIRONMENT BORLAND DELPHI 7.0."

[15] A. S. Putra, "PATENT AS RELEVAN SUPPORT RESEARCH."

[16] A. S. Putra, "PATENT FOR RESEARCH STUDY CASE OF APPLE. Inc."

[17] A. S. Putra, "PATENT PROTECTION FOR APPLICATION INVENT."

[18] A. S. Putra, "QUICK REPORT IN PROPERTY PROGRAMMING."

[19] A. S. Putra, "REVIEW CIRCUIT LAYOUT COMPONENT REQUIREMENT ON ASUS NOTEBOOK."

[20] A. S. Putra, "REVIEW TRADEMARK PATENT FOR INDUSTRIAL TECHNOLOGY BASED 4.0."

[21] A. S. Putra, "TOOLBAR COMPONENT PALLETTE IN OBJECT ORIENTED PROGRAMMING."

[22] A. S. Putra, "WORKING DIRECTORY SET FOR PARADOX 7."

[23] A. S. Putra, "ZQUERY CONNECTION IMPLEMENTED PROGRAMMING STUDI CASE PT. BANK BCA Tbk."

[24] A. S. Putra, D. R. Aryanti, and I. Hartati, "Metode SAW (Simple Additive Weighting) sebagai Sistem Pendukung Keputusan Guru Berprestasi (Studi Kasus: SMK Global Surya)," in Prosiding Seminar Nasional Darmajaya, 2018, vol. 1, no. 1, pp. 85-97.

[25] A. S. Putra and O. M. Febriani, "Knowledge Management Online Application in PDAM Lampung Province," in Prosiding International conference on Information Technology and Business (ICITB), 2018, pp. 181-187.

[26] A. S. Putra, O. M. Febriani, and B. Bachry, "Implementasi Genetic Fuzzy System Untuk Mengidentifikasi Hasil Curian Kendaraan Bermotor Di Polda Lampung," SIMADA (Jurnal Sist. Inf. dan Manaj. Basis Data), vol. 1, no. 1, pp. 21-30, 2018.

[27] A. S. Putra, H. Sukri, and K. Zuhri, "Sistem Monitoring Realtime Jaringan Irigasi Desa (JIDES) Dengan Konsep Jaringan Sensor Nirkabel," IJEIS (Indonesian J. Electron. Instrum. Syst., vol. 8, no. 2, pp. 221-232.

[28] D. P. Sari, O. M. Febriani, and A. S. Putra, "Perancangan Sistem Informasi SDM Berprestasi pada SD Global Surya," in Prosiding Seminar Nasional Darmajaya, 2018, vol. 1, no. 1, pp. 289-294. 